\title{
MECHANISM AND RISK FACTORS OF ADJACENT VERTEBRAL FAILURE POST PERCUTANEOUS VERTEBROPLASTY - A STRAIN ENERGY DENSITY APPROACH
}

\author{
Jaw-Lin Wang*, Chun-Kai Chiang, Been-Der Yang, Yao-Hung Wang, and Jinn Lin
}

\begin{abstract}
Percutaneous vertebroplasty (PV) is an effective treatment procedure for compression fracture of osteoporotic vertebra; however, adjacent vertebral failure (AVF) is a frequently observed complication of PV. The mechanism and risk factors of AVF are not yet clear and this problem has attracted a lot of research effort in the medical community. The purpose of this study is to analyze the mechanism and risk factors of AVF post cement augmentation using a strain energy density (SED) approach. Fresh porcine spine specimens (L1-L5) were used. The effect of cement augmentation on the SED of vertebral bodies (VB), including the damaged VB and both adjacent cranial and caudal VBs, was analyzed. The result showed that the SED of the adjacent VBs did not increase after cement augmentation; however, the accumulated energy in the VBs of the whole spine motion segment decreased significantly after cement augmentation. This globally reduced energy is speculated to be absorbed by the disc between VBs. It is reasonable to believe that AVF may be initiated from the stressed disc. This study also suggests that poor bone quality and flexion compression are the two risk factors for AVF.
\end{abstract}

Key Words: strain energy density, percutaneous vertebroplasty, adjacent vertebral failure, bone quality

\section{INTRODUCTION}

More than 500,000 patients a year suffer from osteoporotic vertebra compression fracture $(\mathrm{OVCF})$ in the United States (Melton et al., 1989). OVCF may impair mobility and cause persistent pain. Non-invasive treatments of OVCF include analgesics, bed rest, and external bracing; however, progressive kyphosis, insomnia, prolonged pain, depression, and disability are still frequently observed in spite of the treatment. Since the weakening strength of cancellous bone

*Corresponding author. (Te1: 886-2-33665269; Fax: 886-223687573; Email: jlwang@ntu.edu.tw)

J. L. Wang, C. K. Chiang, B. D. Yang are with the Institute of Biomedical Engineering, National Taiwan University, Taipei 106 , Taiwan.

Y. H. Wang is with the Department of Medical Imaging, National Taiwan University Hospital, Taipei 100, Taiwan.

J. Lin is with the Department of Orthopedic Sugery, National Taiwan University Hospital, Taipei 100, Taiwan. resulting from the loss of bone mineral is the main contribution to OVCF, surgeons often resort to surgical procedures to restore the mechanical strength of the fractured vertebral body (VB). Percutaneous vertebroplasty $(\mathrm{PV})$ is one of these procedures, which is used to restore mechanical strength by means of cement augmentation inside the fractured VB.

$\mathrm{PV}$ is used to treat severe osteoporosis (Alvarez et al., 2005; 2006), hemangiomas (Ahn et al., 2005), metastasis (Gangi et al., 1994) and recently, the burst fracture injury (Verlaan et al., 2005). The back pain can be relieved after the surgery (Bostrom et al., 1997; Cotten et al., 1996; Mathis et al., 1998). The advantages of the cement augmentation are in two aspects. First, the prophylactic augmentation increases the stability of the osteoporotic vertebra to reduce the risk of injury. Second, the augmentation relieves the pain and restores the mechanical function of the injured vertebra to prevent further collapse.

Adjacent vertebral failure (AVF) is one of the 
two major complications of PV (the other one is cement leakage during surgery). To reduce AVF complications, many research efforts have been made to understand its mechanism. A biomechanical investigation on AVF complication reported (Berlemann et al., 2002) that the stiffness of osteoporotic VB increased by $174 \%$; however, the failure strength of a two-vertebra motion segment was lower than that of an untreated motion segment, post augmentation. Using the finite element analysis approach, Polikeit et al. (Polikeit et al., 2003) reported increased strain on the adjacent VB post augmentation. On the other hand, an in vitro biomechanics study showed the strain on the adjacent vertebra is not significantly increased statistically (Kayanja et al., 2005). Despite these research efforts, the mechanism of AVF is still not yet clear.

It is observed that the mechanism of AVF involves the local fracture of an individual VB and the global "adjacent" effect between VBs. In previous spine research, the stress/strain on the individual VB and the stiffness/strength/displacement of the whole motion segment are the two most frequently used indices for the risk analysis of VB fracture (Kayanja et $a l ., 2004)$. The stress/strain index can provide the detailed local mechanics of VB fracture; but it is not adequate to describe the global behavior of the spine motion segment. On the other hand, the stiffness/ strength/displacement index can describe the global mechanics of the motion segment, but it lacks the capability of describing the detailed VB fracture mechanics. Such exclusive properties of these two indices make them inefficient for AVF mechanism investigation.

The objective of this study is to investigate the mechanism of AVF using a strain energy density (SED) approach to resolve the index inefficiency. Strain energy density is a scalar measure representing the combination effect of stress and strain. The distortion and dilation SED describe the different types of material deformation. The distortion SED indicates that the deformation is more likely to shape distortion, while the dilatation SED indicates that the material suffers from volume change. By accumulating the local SED indices among the studied vertebrae, the accumulated energy can provide a means to address the global behavior of the object. Because of its dual characteristics, SED is widely used in the analysis of fracture mechanics of engineering material.

In this study, the strain energy density per Newton force $(\mathrm{SED} / \mathrm{N})$ is used as an index of injury potential for VB. To identify the mechanism of AVF, two hypotheses related to the SED/N of VB are tested. First, the SED/N of the adjacent VB increases post augmentation. Second, the SED/N of the damaged

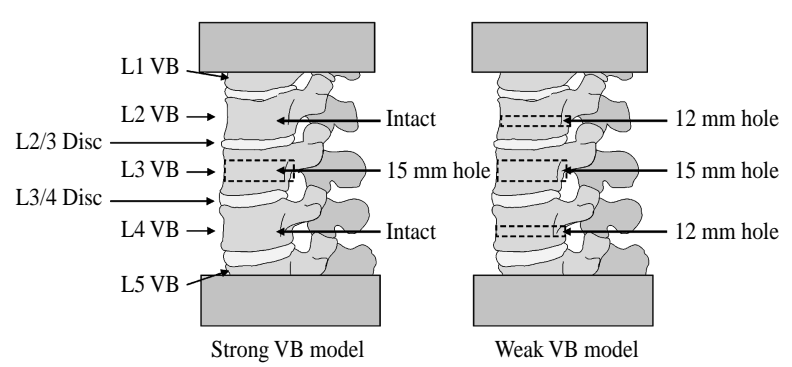

Fig. 1 The schematic of strong VB model and weak VB model. The L1 and L5 VB were molded with quick setting epoxy. A $15 \mathrm{~mm}$ diameter hole was drilled anteroposteriorly through the L3 VB to simulate the loss of strength in a compression fractured osteoporotic vertebrae. The L2 and L4 remained intact in strong VB model. A $12-\mathrm{mm}$ diameter hole was drilled anteroposteriorly through the L2 and L4 VB in weak VB model.

VB decreases post augmentation. The first hypothesis can reveal if the adjacent VB suffers from increased SED/N energy inside its local volume that may lead to AVF post augmentation. Combining the results of both hypotheses, it can be inferred how the energy sharing occurs globally among the spine motion segments pre and post augmentation which can help to identify the mechanism of AVF. Three factors, including VB level, bone quality and loading condition (pure compression vs. flexion compression), on the distribution of SED/N within damaged and adjacent VB were also analyzed. The results can be used to identify the risk factors of AVF.

\section{METHODS \& MATERIALS}

\section{Specimen Preparation}

Fresh porcine lumbar spine specimens (L1/L5) were obtained immediately following death. The specimens were harvested from 6-month-old swine. Each specimen was carefully cleaned of muscle tissue, placed in double plastic bags, and frozen at $-20^{\circ} \mathrm{C}$. The specimen was thawed, and the L1 and L5 VB were molded with quick setting epoxy. A $15 \mathrm{~mm} \mathrm{di-}$ ameter hole was drilled anteroposteriorly through the L3 VB to mimic the strength weakening due to OVCF. Two motion segment models, the strong VB model and the weak VB model, were simulated. In the strong $\mathrm{VB}$ model, the $\mathrm{L} 2$ and $\mathrm{L} 4$ remained intact. In the weak VB model, a 12-mm diameter hole was drilled anteroposteriorly through the L2 and L4 VB (Fig. 1). The specimens were removed from the freezer and kept at room temperature for 6 hours before experiments. During the experiments, the specimens were wrapped with gauze and saline. Before the experiments, 3-axial strain gauge rosettes (KFG-1120-D17-11N50C2, Kyowa Electronics Instruments, 


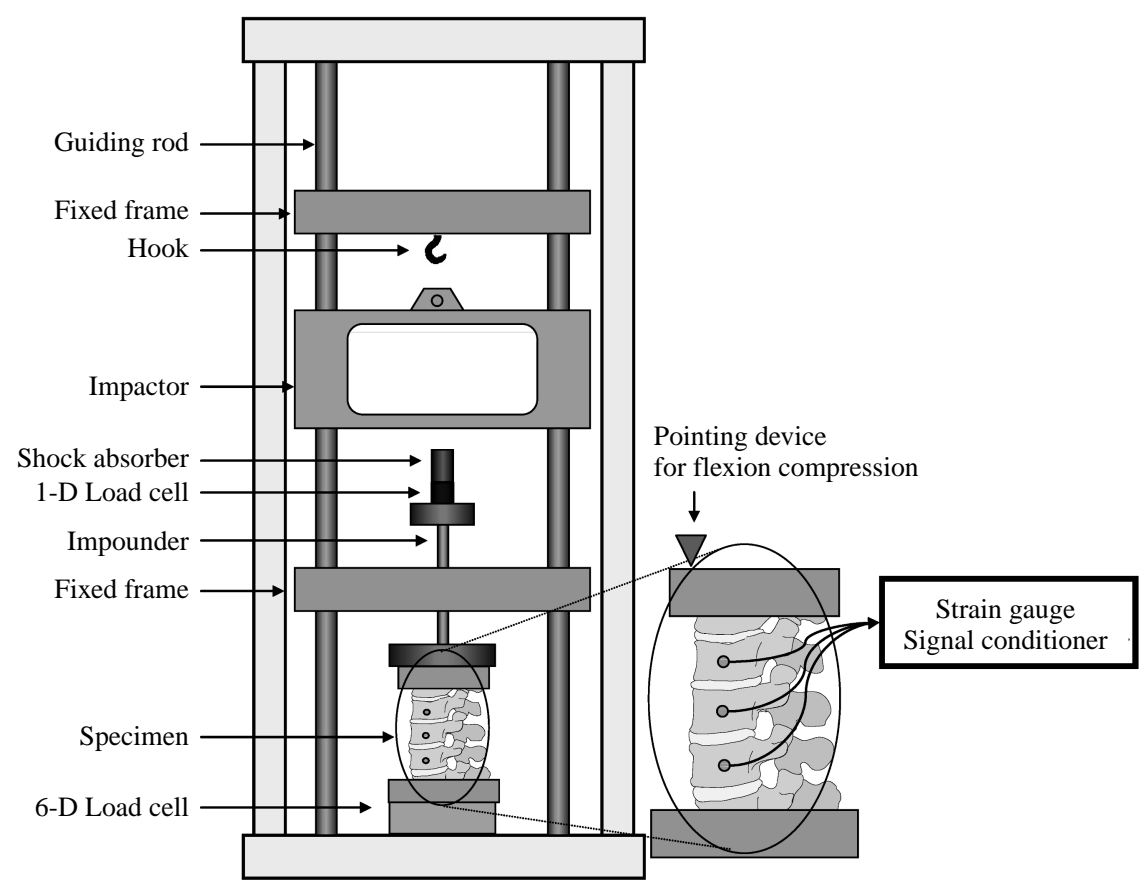

Fig. 2 The drop tower type testing apparatus and strain gauge rosettes on the vertebras. The impactor was guided by two rods to give a vertical motion. The specimen was mounted vertically below the impounder and above the load cell. Three strain gauge rosettes were applied on the lateral cortical shells of L2, L3 and L4 VB.

Tokyo, Japan) were glued on the lateral surfaces of the cortical shells of L2, L3 and L4 VB (Fig. 2) (Buttermann et al., 1991, 1992, 1994).

\section{Testing Apparatus}

A "drop-tower type" testing apparatus was used for the testing (Fig. 2). The impact energy was created by the free fall of the impactor and transmitted to the specimen through the impounder. The shock absorber was placed on the top of the impounder to control the impact contact period at approximately 20 milli-seconds. A uni-axial load cell (9021 A, Kistler Instrumente, Winterthur, Switzerland) was mounted below the shock absorber to detect the impact force. A 16-channel modulated amplifier (3B series Signal Conditioning, Ana$\log$ Devices, Norwood, MA, USA) was used for the strain gauge signal conditioning. Half seconds of data were recorded at $10 \mathrm{kHz}$ sampling rate. The signal was low-pass filtered at $500 \mathrm{~Hz}$ frequency using the Butterworth filtering algorithm. In this study, the muscle recruitment is not replicated. Since the height of the tested specimen was relatively short, the instability due to the long spinal column can be ignored.

\section{Experimental Protocol}

Three groups were tested. Group 1 was the strong VB loaded with pure compression $(n=10)$. Group 2 was the weak VB loaded with pure compression $(n=$ 8 ), and Group 3 was the weak VB loaded with flexion compression $(n=8)$. A $3.6 \mathrm{~J}$ input energy was applied to the specimens (loading height: $30 \mathrm{~mm}$, and weight: $12 \mathrm{~kg}$ ). The vertical load was evenly distributed on the top of specimen during pure compression. A pointing device was applied at the top of the specimens along the trajectory of the anterior cortical surfaces of vertebral bodies during flexion compression. The augmentation of standard PV was simulated by filling the $15-\mathrm{mm}$ diameter hole with bone cement. The force, moment, and strains responses of all three groups of specimens during the loading were collected both pre and post augmentation.

\section{SED Data Analysis}

Assuming the stress-strain field of the cortical shell of VB to be the plain strain, the three principal stresses $\left(\sigma_{1}, \sigma_{2}, \sigma_{3}\right)$ of the cortical bone can be expressed as:

$$
\begin{aligned}
& \sigma_{1}= E\left[\frac{\varepsilon_{A}+\varepsilon_{C}}{2(1-v)}+\frac{1}{2(1+v)}\right. \\
&\left.\cdot \sqrt{\left(\varepsilon_{A}-\varepsilon_{C}\right)^{2}+\left(2 \varepsilon_{B}-\varepsilon_{A}-\varepsilon_{C}\right)^{2}}\right] \\
& \sigma_{2}=E\left[\frac{\varepsilon_{A}+\varepsilon_{C}}{2(1-v)}-\frac{1}{2(1+v)}\right. \\
&\left.\cdot \sqrt{\left(\varepsilon_{A}-\varepsilon_{C}\right)^{2}+\left(2 \varepsilon_{B}-\varepsilon_{A}-\varepsilon_{C}\right)^{2}}\right]
\end{aligned}
$$




$$
\sigma_{3}=v\left(\sigma_{1}+\sigma_{2}\right)
$$

where $\varepsilon_{A}, \varepsilon_{B}, \varepsilon_{C}$ are the strains measured from the strain gauge rosette, $E=11.032 \mathrm{GPa}$, and $v=0.3$ for the cortical bone (Cao et al., 2001). Once the principal stresses are known and if we assume the stiffness of the cortical bone to be isometric, the total, dilatation and distortion SED can be obtained as follows:

$$
\begin{aligned}
& \text { Total SED }=\frac{1}{2 E}\left[I_{1}^{2}-2(1+v) I_{2}\right] \\
& \text { Dilatation SED }=\frac{1-2 v}{6 E}\left(\sigma_{1}+\sigma_{2}+\sigma_{3}\right)^{2} \\
& \text { Distortion SED }=\text { Total SED - Dilatation SED, }
\end{aligned}
$$

where $I_{1}=\sigma_{1}+\sigma_{2}+\sigma_{3}, I_{2}=\sigma_{1} \sigma_{2}+\sigma_{1} \sigma_{3}+\sigma_{2} \sigma_{3}$ and $I_{3}=\sigma_{1} \sigma_{2} \sigma_{3}$. Using the above energy equations, the maximum total, dilatation and distortion SED of the interested VB, including the adjacent cranial VB, damaged VB, and adjacent caudal VB, were collected pre and post augmentation. These collected SED were further normalized using the maximum force during the loading history, i.e. SED/N, for data analysis.

\section{Energy Accumulation within VB}

Assuming the vertebral body (VB) is an elliptic cylinder (Fig. 3), and the vertical load is evenly distributed, the relation between vertical force $P$ and compressive stress $\left(\sigma_{Z 1}, \sigma_{Z 2}\right)$ is:

$$
P=\frac{\pi}{4} \cdot A \cdot B \cdot \sigma_{Z 1}+\frac{\pi}{4} \cdot(A \cdot B-a \cdot b) \cdot \sigma_{Z 2} .
$$

Assuming the strain energy density (SED) is composed of the compressive stress only, the SED of the cortical shell in terms of compressive stress $\left(\sigma_{Z 2}\right)$ and elastic modulus of the cortical shell $\left(E_{2}\right)$ is:

$$
\mathrm{SED}=\frac{\sigma_{Z 2}^{2}}{2 E_{2}}
$$

The total energy accumulated in the VB $(W)$ includes the energy in cancellous bone and cortical shell, and can be expressed as follows:

$$
W=\frac{\pi}{4} \cdot a \cdot b \cdot l \cdot \frac{\sigma_{Z 1}^{2}}{2 E_{1}}+\frac{\pi}{4} \cdot(A \cdot B-a \cdot b) \cdot l \cdot \frac{\sigma_{Z 2}^{2}}{2 E_{2}} .
$$

Assuming the vertical strain of cancellous bone and cortical shell are equal $\left(\varepsilon_{Z}=\frac{\sigma_{Z 1}}{E_{1}}=\frac{\sigma_{Z 2}}{E_{2}}\right)$, the total energy in the VB in terms of SED of the cortical shell can be derived as:

$$
W=\frac{\pi}{4} \cdot A \cdot B \cdot\left[1-\left(1-\frac{E_{1}}{E_{2}}\right) \cdot \frac{a \cdot b}{A \cdot B}\right] \cdot l \cdot \mathrm{SED}
$$

where

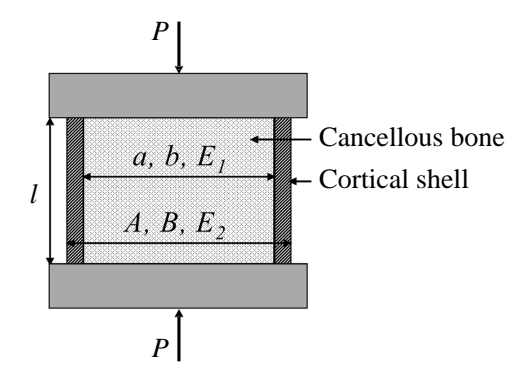

Fig. 3 Vertebral body schematic. The vertical load $P$ is evenly distributed. $A, B$ : diameter of external long and short axis, $a, b$ : diameter of internal long and short axis, $E_{1}$ : elastic modulus of cancellous bone, $E_{2}$ : elastic modulus of cortical shell, $l$ : height of VB.

$a, b:$ diameter of internal (cancellous bone) long and short axis,

$A, B$ : diameter of external (cortical shell) long and short axis,

$E_{1}$ : elastic modulus of cancellous bone,

$E_{2}$ : elastic modulus of cortical shell,

$\sigma_{Z 1}$ : compressive stress in cancellous bone,

$\sigma_{Z 2}$ : compressive stress in cortical shell,

$\varepsilon_{Z} \quad$ : vertical strain of cancellous bone and cortical shell,

$l$ : height of VB,

$P \quad$ : vertical force,

SED: strain energy density of the cortical shell,

and

$W \quad$ : total energy in the VB.

\section{Statistical Analysis}

One-tailed paired t-test was performed to find the effect of augmentation, level of VB and loading condition on the SED/N. One-tailed independent ttest was performed to find the effect of bone quality on the SED/N. All tests were considered to be significant at $\alpha=0.05$.

\section{RESULTS}

The result of the first hypothesis test, as shown in Table 1 , indicated that the SED/N energy increase in both adjacent VBs post augmentation was not statistically significant. The SED/N of strong L2 (Group 1) increased post augmentation, but the amount of increase was minor (less than $1 \mathrm{~J} / \mathrm{m}^{3} / \mathrm{N}$ ). The effect of augmentation on the increase of SED/N of Group 2 and 3 tests was not statistically significant. The effect of augmentation on the SED/N of L4 was also not statistically significant.

The result of the second hypothesis test, as 


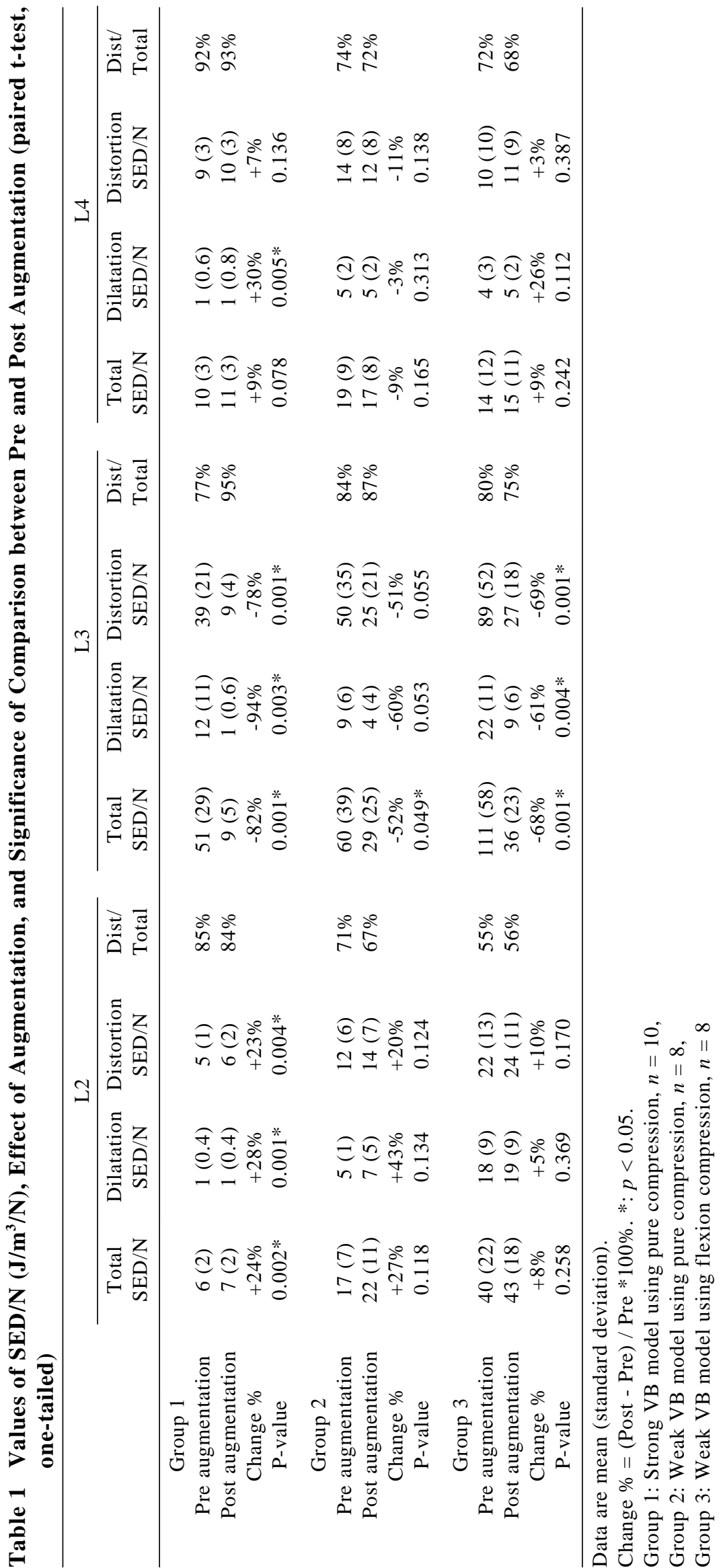




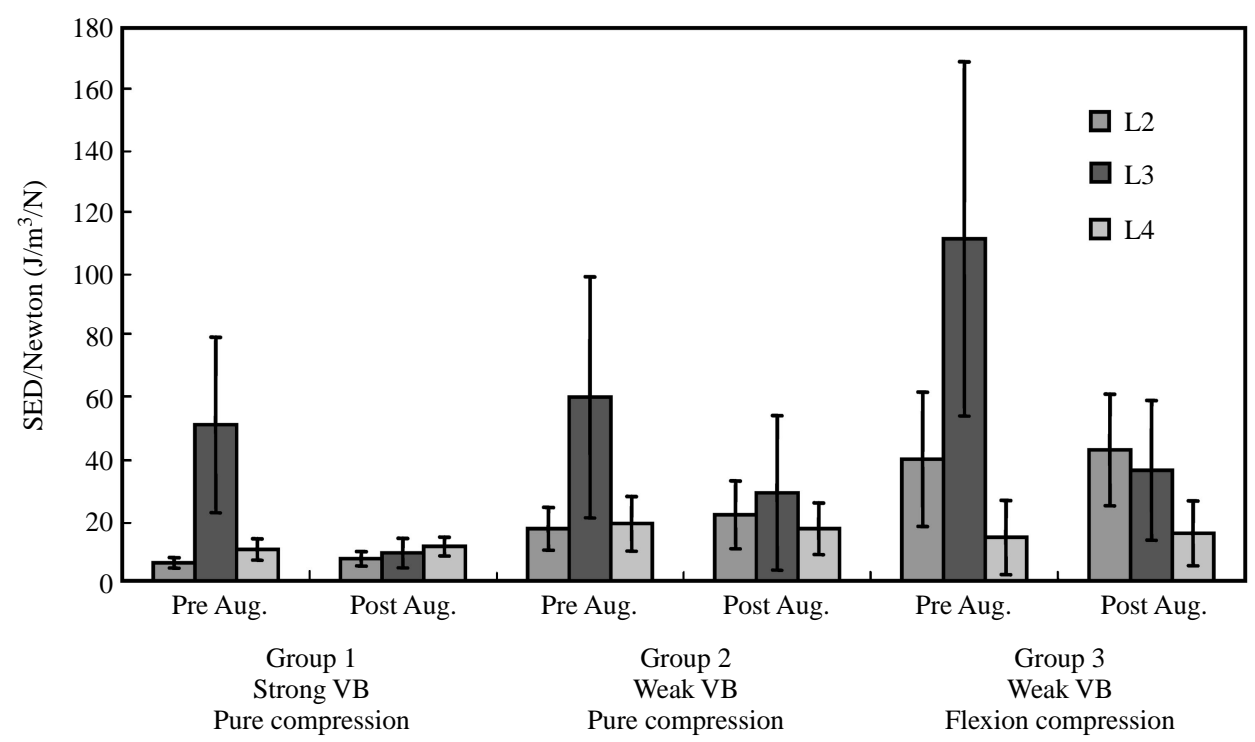

Fig. 4 The $\mathrm{SED} / \mathrm{N}\left(\mathrm{J} / \mathrm{m}^{3} / \mathrm{N}\right)$ of three groups of test pre and post cement augmentation

shown in Table 1, indicated that the SED/N energy was reduced by $52 \%$ to $82 \%$ post augmentation; and the decrease was statistically significant in all three test groups. The SED/N of all three VBs pre and post cement augmentation is also shown in Fig. 4 graphically.

\section{Effect of VB Level}

The SED/N of L2 was less than L4 during pure compression (Group 1), but it was higher than L4 during flexion compression (Group 3). The SED/N of L3 was higher than L2 and L4 pre augmentation. However, the SED/N of L3 was not statistically different from L2 or L4 post augmentation during most of the tests. The highest SED/N post augmentation was located at L2 during flexion compression (Table 2).

\section{Effect of Bone Quality}

The SED/N of L2, L3 and L4 of weak VB model was higher than the one of strong VB model post augmentation (Table 3).

\section{Effect of Loading Condition}

The SED/N of L2 during flexion compression was always higher than during pure compression both before and after the cement augmentation. The SED/ $\mathrm{N}$ of L3 was significantly increased by the flexion compression only pre augmentation, but not post augmentation. The effect of loading condition on L4 was not significant either pre or post augmentation (Table 4).

\section{Energy Accumulation within VB}

Assuming the identical size for all three VBs, the change of energy accumulation in VBs post augmentation was calculated from the results of Table 1 , which is shown in Table 5. The test result showed $59 \%, 30 \%$, and $43 \%$ decrease of total energy in the VBs post augmentation for the Group 1, Group 2, and Group 3 tests, respectively.

\section{DISCUSSION}

According to the result of the tests of the first hypothesis, it is found that the SED of the adjacent VB post augmentation does not increase significantly. The result confirms the in vitro biomechanics investigation (Kayanja et al., 2005). The result implies that the local behavior of the adjacent VB is not the main factor causing the AVF complication, since the cement augmentation treatment of PV does not significantly increase the SED energy in either adjacent VB.

On the other hand, the result shows that the accumulated SED energy of the three VBs in the tested spine motion segment decreases significantly. This globally reduced energy is speculated to be absorbed by other parts of the motion segment, i.e., the discs between the VBs. The increased energy in the disc would increase the stress and strain on annulus fibrosus and adjacent endplates. The increase of disc pressure was confirmed in the in vitro cadaveric study (Farooq et al., 2005) and finite element analysis (Baroud et al., 2003; Keller et al., 2005; Polikeit et al., 2003); and the observation of the stressed endplate 
Table 2 Effect of Level, and Significance of Comparison of L2 vs. L4, L3 vs. L2, L3 vs. L4 Vertebral Body (paired t-test, one-tailed)

\begin{tabular}{|c|c|c|c|c|c|c|c|c|c|}
\hline & \multicolumn{3}{|c|}{ L2 vs. L4 } & \multicolumn{3}{|c|}{ L3 vs. L2 } & \multicolumn{3}{|c|}{ L3 vs. L4 } \\
\hline & $\begin{array}{c}\text { Total } \\
\text { SED/N }\end{array}$ & $\begin{array}{c}\text { Dilatation } \\
\text { SED/N }\end{array}$ & $\begin{array}{l}\text { Dilatation } \\
\text { SED/N }\end{array}$ & $\begin{array}{l}\text { Total } \\
\text { SED/N }\end{array}$ & $\begin{array}{c}\text { Dilatation } \\
\text { SED/N }\end{array}$ & $\begin{array}{l}\text { Dilatation } \\
\text { SED/N }\end{array}$ & $\begin{array}{c}\text { Total } \\
\text { SED/N }\end{array}$ & $\begin{array}{c}\text { Dilatation } \\
\text { SED/N }\end{array}$ & $\begin{array}{l}\text { Dilatation } \\
\text { SED/N }\end{array}$ \\
\hline \multicolumn{10}{|c|}{$\begin{array}{c}\text { Pre augmentation } \\
\text { Group } 1\end{array}$} \\
\hline Change \% & $-43 \%$ & $+6 \%$ & $-48 \%$ & $+771 \%$ & $+1248 \%$ & $+685 \%$ & $+395 \%$ & $+1328 \%$ & $+312 \%$ \\
\hline $\begin{array}{l}\text { P-value } \\
\text { Group } 2\end{array}$ & $0.002 *$ & 0.388 & $0.001 *$ & $0.000 *$ & $0.000 *$ & $0.000 *$ & $0.000^{*}$ & $0.000 *$ & $0.000 *$ \\
\hline Change \% & $-9 \%$ & $+3 \%$ & $-13 \%$ & $+253 \%$ & $+88 \%$ & $+322 \%$ & $+222 \%$ & $+93 \%$ & $+268 \%$ \\
\hline $\begin{array}{l}\text { P-value } \\
\text { Group } 3\end{array}$ & 0.365 & 0.437 & 0.337 & $0.011 *$ & $0.045^{*}$ & $0.011 *$ & $0.015^{*}$ & $0.041 *$ & $0.015^{*}$ \\
\hline Change $\%$ & $+180 \%$ & $+355 \%$ & $+113 \%$ & $+182 \%$ & $+26 \%$ & $+308 \%$ & $+687 \%$ & $+473 \%$ & $+769 \%$ \\
\hline P-value & $0.010^{*}$ & $0.002 *$ & $0.039 *$ & $0.008^{*}$ & 0.220 & $0.005^{*}$ & $0.001 *$ & $0.000 *$ & $0.001 *$ \\
\hline \multicolumn{10}{|c|}{$\begin{array}{l}\text { Post augmentation } \\
\text { Group } 1\end{array}$} \\
\hline Change \% & $-36 \%$ & $4 \%$ & $-40 \%$ & $+26 \%$ & $-39 \%$ & $+42 \%$ & $-19 \%$ & $-37 \%$ & $-15 \%$ \\
\hline $\begin{array}{l}\text { P-value } \\
\text { Group } 2\end{array}$ & $0.001 *$ & 0.435 & $0.000 *$ & 0.160 & $0.010 *$ & 0.070 & 0.070 & 0.060 & 0.130 \\
\hline Change \% & $+27 \%$ & $+52 \%$ & $+17 \%$ & $+33 \%$ & $-47 \%$ & $+73 \%$ & $+69 \%$ & $-19 \%$ & $+102 \%$ \\
\hline $\begin{array}{l}\text { P-value } \\
\text { Group } 3\end{array}$ & 0.198 & 0.067 & 0.304 & 0.208 & 0.096 & 0.075 & 0.114 & 0.264 & 0.072 \\
\hline Change $\%$ & $+175 \%$ & $+281 \%$ & $+126 \%$ & $-16 \%$ & $-53 \%$ & $+13 \%$ & $+132 \%$ & $+80 \%$ & $+157 \%$ \\
\hline P-value & $0.008 *$ & $0.003 *$ & $0.031 *$ & 0.276 & $0.018 *$ & 0.333 & $0.030^{*}$ & 0.084 & $0.026^{*}$ \\
\hline
\end{tabular}

Change $\%=(\mathrm{L} 2-\mathrm{L} 4) / \mathrm{L} 4 * 100 \%,(\mathrm{~L} 3-\mathrm{L} 2) / \mathrm{L} 2 * 100 \%,(\mathrm{~L} 3-\mathrm{L} 4) / \mathrm{L} 4 * 100 \%, *: P<0.05$.

Group 1: Strong VB model, pure compression, Group 2: Weak VB model, pure compression, Group 3: Weak VB model, flexion compression.

Table 3 Increased Percentages of SED/N and Significance from Weak to Strong VB model during Pure Compression (independent t-test, one-tailed)

\begin{tabular}{|c|c|c|c|c|c|c|c|c|c|}
\hline & \multicolumn{3}{|c|}{$\mathrm{L} 2$} & \multicolumn{3}{|c|}{ L3 } & \multicolumn{3}{|c|}{$\mathrm{L} 4$} \\
\hline & $\begin{array}{c}\text { Total } \\
\text { SED/N }\end{array}$ & $\begin{array}{c}\text { Dilatation } \\
\text { SED/N }\end{array}$ & $\begin{array}{c}\text { Dilatation } \\
\text { SED/N }\end{array}$ & $\begin{array}{c}\text { Total } \\
\text { SED/N }\end{array}$ & $\begin{array}{l}\text { Dilatation } \\
\text { SED/N }\end{array}$ & $\begin{array}{c}\text { Dilatation } \\
\text { SED/N }\end{array}$ & $\begin{array}{c}\text { Total } \\
\text { SED/N }\end{array}$ & $\begin{array}{c}\text { Dilatation } \\
\text { SED/N }\end{array}$ & $\begin{array}{c}\text { Dilatation } \\
\text { SED/N }\end{array}$ \\
\hline \multicolumn{10}{|c|}{ Pre augmentation } \\
\hline Change \% & $+190 \%$ & $+465 \%$ & $+142 \%$ & $+18 \%$ & $-22 \%$ & $+30 \%$ & $+81 \%$ & $+482 \%$ & $+46 \%$ \\
\hline $\mathrm{P}$-value & $0.001 *$ & $0.000 *$ & $0.007 *$ & 0.298 & 0.266 & 0.216 & $0.017 *$ & $0.001 *$ & 0.087 \\
\hline \multicolumn{10}{|c|}{ Post augmentation } \\
\hline Change \% & $+199 \%$ & $+530 \%$ & $+137 \%$ & $+217 \%$ & $+453 \%$ & $+189 \%$ & $+52 \%$ & $+332 \%$ & $+22 \%$ \\
\hline P-value & $0.004 *$ & $0.008 *$ & $0.005^{*}$ & $0.032 *$ & $0.023^{*}$ & $0.035^{*}$ & $0.050^{*}$ & $0.000^{*}$ & 0.238 \\
\hline
\end{tabular}

Change $\%=($ Weak - Strong $) /$ Strong $* 100 \%, *: p<0.05$.

may explain why cement leakage into the disc would produce a higher risk of AVF (Lin et al., 2004). From the increased energy absorption of the disc, it is reasonable to believe AVF may be initiated from the stressed disc and the endplate.

Using strain gauge to measure strain was a reliable technique for VB (Frei et al., 2001, 2002; Hongo et al., 1999; Shah et al., 1978) and facet joint (Buttermann et al., 1991, 1992). To validate our strain gauge measurement, we checked; first, if the energy accumulation in the VB was comparable to the energy input; and second, if the strain measured in this study was close to the range reported in the literature. Assuming the three VBs were $38 \mathrm{~mm}$ wide, $25 \mathrm{~mm}$ deep, $35 \mathrm{~mm}$ high, and $1 \mathrm{~mm}$ thick elliptical cylinders (based on the estimate of L3 specimen), the material property of VB was uniform, the material property of cancellous bone was $100 \mathrm{MPa}$, and the volume did not change post augmentation, the total energy accumulation in the L2, L3 and L4 VB was calculated to be $0.51 \mathrm{~J}$ pre augmentation and $0.29 \mathrm{~J}$ post augmentation (using results of Group 3 test). This 
Table 4 Increased Percentages of SED/N and Significance from Flexion Compression to Pure Compression within Weak VB model (paired t-test, one-tailed)

\begin{tabular}{|c|c|c|c|c|c|c|c|c|c|}
\hline & \multicolumn{3}{|c|}{ L2 } & \multicolumn{3}{|c|}{ L3 } & \multicolumn{3}{|c|}{ L4 } \\
\hline & $\begin{array}{c}\text { Total } \\
\text { SED/N }\end{array}$ & $\begin{array}{c}\text { Dilatation } \\
\text { SED/N }\end{array}$ & $\begin{array}{c}\text { Dilatation } \\
\text { SED/N }\end{array}$ & $\begin{array}{c}\text { Total } \\
\text { SED/N }\end{array}$ & $\begin{array}{c}\text { Dilatation } \\
\text { SED/N }\end{array}$ & $\begin{array}{c}\text { Dilatation } \\
\text { SED/N }\end{array}$ & $\begin{array}{c}\text { Total } \\
\text { SED/N }\end{array}$ & $\begin{array}{c}\text { Dilatation } \\
\text { SED/N }\end{array}$ & $\begin{array}{c}\text { Dilatation } \\
\text { SED/N }\end{array}$ \\
\hline \multicolumn{10}{|c|}{ Pre augmentation } \\
\hline Change \% & $+133 \%$ & $+257 \%$ & $+82 \%$ & $+86 \%$ & $+140 \%$ & $+76 \%$ & $-24 \%$ & $-19 \%$ & $-25 \%$ \\
\hline P-value & $0.012 *$ & $0.003 *$ & $0.036 *$ & $0.016^{*}$ & $0.002 *$ & $0.029 *$ & 0.204 & 0.274 & 0.183 \\
\hline \multicolumn{10}{|c|}{ Post augmentation } \\
\hline Change \% & $+98 \%$ & $+163 \%$ & $+66 \%$ & $+26 \%$ & $+133 \%$ & $+9 \%$ & $-9 \%$ & $5 \%$ & $-14 \%$ \\
\hline P-value & $0.004 *$ & $0.002 *$ & $0.018 *$ & 0.110 & $0.006 *$ & 0.332 & 0.370 & 0.433 & 0.300 \\
\hline
\end{tabular}

Change $\%=($ Flexion - Comp) $/$ Comp $* 100 \%, *: p<0.05$.

Table 5 Effect of Augmentation on the Energy Accumulation in Vertebral Body and its Significance (paired t-test, one-tailed)

\begin{tabular}{cccc}
\hline & $\begin{array}{c}\text { Total } \\
\text { SED }\end{array}$ & $\begin{array}{c}\text { Dilatation } \\
\text { SED }\end{array}$ & $\begin{array}{c}\text { Dilatation } \\
\text { SED }\end{array}$ \\
\hline Group 1 & & & \\
Change \% & $-59 \%$ & $-81 \%$ & $-53 \%$ \\
P-value & $0.000 *$ & $0.000 *$ & $0.000^{*}$ \\
Group 2 & & & \\
Change \% & $-30 \%$ & $-19 \%$ & $-32 \%$ \\
P-value & 0.065 & 0.127 & 0.067 \\
Group 3 & & & \\
Change \% & $-43 \%$ & $-26 \%$ & $-49 \%$ \\
P-value & $0.002 *$ & $0.012 *$ & $0.002 *$ \\
\hline
\end{tabular}

Change $\%=($ Post - Pre $) /$ Pre $* 100 \%, *: p<0.05$.

Group 1: Strong VB model using pure compression, $n=10$, Group 2: Weak VB model using pure compression, $n=8$, Group 3: Weak VB model using flexion compression, $n=$ 8.

amount was reasonably smaller than the magnitude of energy input (3.6 J). The difference between energy accumulation in the VBs and energy input was speculated to be stored by the rest of the spine tissue (e.g., the discs) and the shock absorber of the testing apparatus. The principal strain of weak L2 VB during pure compression was $2,400 \mu \varepsilon$ at $1,600 \mathrm{~N}$ (stiffness $=1.5 \mu \varepsilon / \mathrm{N}$, Group 2 test, post augmentation). This magnitude was close to the range of the human cadaver study ( $650 \mu \varepsilon$ at $490 \mathrm{~N}$ loading, stiffness $=1.3$ $\mu \varepsilon / \mathrm{N}$ ) (Hongo et al., 1999). The results of the current study approximately represent human VB properties.

The morphology of porcine lumbar spine is analogous to the human spine (McLain et al., 2002). One significant difference of porcine vertebrae from human vertebrae is the morphology of the facet joint. The morphology of the porcine lumbar anterior articular process (analogous to the human superior articular process) is like an arch surrounding the adjacent cranial posterior articular process (analogous to the human inferior articular process). This morphological difference may put the porcine facet joint under higher load sharing especially at shear loading. Since the loading condition of our testing was primarily in axial compression, the effect of the morphological difference in the current study can regarded as minimal. There are several well know advantages and disadvantages in using animal vertebrae. The quality of animal vertebrae is consistent, and the variation of result is small. It is therefore better to use animal specimens instead of costly human specimen if the nature of the paper is to validate a hypothesis. It is very difficult, if not impossible, to find osteoporotic animal vertebra. The current study used the method of drilling a hole with a fixed dimension to simulate the weakening of vertebrae. This methods gives a consistent property of weakening of the vertebrae. Using human osteoporotic motion segments for this study is also feasible; however, more specimens are need to get a statistically significantly result, at much greater cost. The use of porcine vertebrae serves the purpose of this study, i.e., validating the illustrated hypothesis.

As reported, the peak compressive load of the spine is greater than 5,500 $\mathrm{N}$ in trick falls (Essendrop et al., 2004), 8,600 $\mathrm{N}$ in blocking maneuvers for football linemen (Gatt et al., 1997), and $17,000 \mathrm{~N}$ for weight lifters (Cholewicki et al., 1991). In this study, the input energy was 3.6 J which leads to the resultant force $1,600 \mathrm{~N}$. It is clear that the loading used in this study should be able to mimic the force applied on the spinal column by a superincumbent body weight and external sudden and medium loading.

The SED is widely used in the analysis of fracture mechanics of engineering materials. Nevertheless, SED has been rarely used in spine biomechanics. Among the few cases observed, it was used to analyze the localized damage of VB (Kopperdahl et al., 
1999) and bone adaptation (Goel et al., 1995) using finite element analysis. The illustration of distortion and dilatation SED was also a new endeavor for spine biomechanical studies. The ratio of distortion and dilatation SED described the types of deformation of materials. The higher ratio of distortion SED over total SED indicated that the deformation was more likely to shape distortion rather than volume change. The ratio of distortion SED over the total SED was highest at L3 during pure compression post augmentation $(95 \%)$, and lowest at weak L2 during flexion compression (55\%). This fact implies that the deformation of L3 is likely to shape distortion after augmentation, and the deformation of weak L2 is likely to change volume during flexion compression.

We found weak VB and flexion compression are the two risk factors for AVF. The weak VB as a risk factor was shown by other clinical observations (Lindsay et al., 2001) and biomechanical testing (Kayanja et al., 2005, 2006; Seino et al., 2003) as well. However, flexion compression as a risk factor has not been solidly established. A clinical observation reported that a higher loss of VB height showed less patient satisfaction post surgery (Alvarez et al., 2005). Greater loss of VB height might induce a larger kyphotic angle, hence leading to a constant flexion compression. The flexion compression will induce a higher strain in the VB, which then leads to post surgery dissatisfaction. A biomechanical study also showed the flexion compression induced higher shear strain on the cortical shell (Kayanja et al., 2004).

Some numerical (Polikeit et al., 2003) and experimental (Kayanja et al., 2005) studies have indicated that AVF was induced by the rise of stress on adjacent VB. We did not find statistically significant increase of SED in the cortical shell of adjacent VB, post augmentation. The summation of energy accumulation within the L2, L3 and L4 VB decreased post augmentation. The decreased energy in the three VB was speculated to be absorbed by the disc. The extra energy in the disc would increase stress and strain on anulus fibrosus and adjacent endplate, hence increasing the risk of VB injury. This result also implies that AVF may be initiated from the peripheral disc tissue, i.e. the endplate. The increase of disc pressure was also confirmed in an in vitro cadaveric study (Farooq et al., 2005) and finite element analysis (Baroud et al., 2003; Keller et al., 2005; Polikeit et al., 2003). This may also explain why cement leakage into the disc would induce a higher risk of AVF (Lin et al., 2004).

\section{CONCLUSIONS}

This study found the energy accumulation within the disc may be the cause of AVF. Strategies such as changing of spine posture or loading pattern that minimize the energy accumulation within a disc can be designed to reduce the risk of AVF. The results of this research suggest that; restoring the natural lordotic posture, preventing flexion motion and reducing the magnitude of external loading seem to be the best strategies to prevent AVF for an already weak VB.

\section{ACKNOWLEDGMENTS}

This study was supported by National Health Research Institute, Taiwan (NHRI-Ex 94-525EI, NHRI-Ex95-9425EI). We appreciate the help in statistical analysis from miss Ya-Wen Kuo.

\section{REFERENCES}

Ahn, H., Jhaveri, S., Yee, A., and Finkelstein, J., 2005, "Lumbar Vertebral Hemangioma Causing Cauda Equina Syndrome: A Case Report," Spine, Vol. 30, No. 21, pp. E662-664.

Alvarez, L., Perez-Higueras, A., Granizo, J. J., de Miguel, I., Quinones, D., and Rossi, R. E., 2005, "Predictors of Outcomes of Percutaneous Vertebroplasty for Osteoporotic Vertebral Fractures," Spine,Vol. 30, No. 1, pp. 87-92.

Alvarez, L., Alcaraz, M., Perez-Higueras, A., Granizo, J. J., de Miguel, I., Rossi, R. E., and Quinones, D., 2006, "Percutaneous Vertebroplasty: Functional Improvement in Patients With Osteoporotic Compression Fractures," Spine, Vol. 31, No. 10, pp. 1113-1118.

Baroud, G., Nemes, J., Heini, P., and Steffen, T., 2003, "Load Shift of The Intervertebral Disc After a Vertebroplasty: a Finite-Element Study," European Spine Journal, Vol. 12, No. 4, pp. 421426.

Berlemann, U., Ferguson, S. J., Nolte, L. P., and Heini, P. F., 2002, "Adjacent Vertebral Failure after Vertebroplasty. A Biomechanical Investigation," Journal of Bone and Joint Surgery-British Edition, Vol. 84, No. 5, pp. 748-752.

Bostrom, M. P., and Lane, J. M., 1997, "Future Directions. Augmentation of Osteoporotic Vertebral Bodies," Spine, Vol. 22, No. 24 Suppl, pp. $38 \mathrm{~S}-42 \mathrm{~S}$.

Buttermann, G. R., Kahmann, R. D., Lewis, J. L., and Bradford, D. S., 1991, “An Experimental Method for Measuring Force on The Spinal Facet Joint: Description and Application of The Method," Journal of Biomechanical Engineering, Vol. 113, No. 4, pp. 375-386.

Buttermann, G. R., Schendel, M. J., Kahmann, R. D., Lewis, J. L., and Bradford, D. S., 1992, "In Vivo Facet Joint Loading of The Canine Lumbar Spine," 
Spine, Vol. 17, No. 1, pp. 81-92.

Buttermann, G. R., Janevic, J. T., Lewis, J. L., Lindquist, C. M., Wood, K. B., and Schendel, M. J., 1994, "Description and Application of Instrumented Staples for Measuring in Vivo Bone Strain," Journal of Biomechanics, Vol. 27, No. 8, pp. 1087-1094.

Cao, K. D., Grimm, M. J., and Yang, K. H., 2001, "Load Sharing Within a Human Lumbar Vertebral Body Using the Finite Element Method," Spine, Vol. 26, No. 12, pp. E253-260.

Cholewicki, J., McGill, S. M., and Norman, R. W., 1991, "Lumbar Spine Loads During the Lifting of Extremely Heavy Weights," Medicine \& Science in Sports \& Exercise, Vol. 23, No. 10, pp. 1179-1186.

Cotten, A., Dewatre, F., Cortet, B., Assaker, R., Leblond, D., Duquesnoy, B., Chastanet, P., and Clarisse, J., 1996, "Percutaneous Vertebroplasty for Osteolytic Metastases and Myeloma: Effects of the Percentage of Lesion Filling and The Leakage of Methyl Methacrylate at Clinical Followup," Radiology, Vol. 200, No. 2, pp. 525-530.

Essendrop, M., Trojel Hye-Knudsen, C., Skotte, J., Faber Hansen, A., and Schibye, B., 2004, "Fast Development of High Intra-abdominal Pressure When a Trained Participant is Exposed to Heavy, Sudden Trunk Loads," Spine, Vol. 29, No. 1, pp. 94-99.

Farooq, N., Park, J. C., Pollintine, P., AnnesleyWilliams, D. J., and Dolan, P., 2005, "Can Vertebroplasty Restore Normal Load-Bearing to Fractured Vertebrae?" Spine, Vol. 30, No. 15, pp. 1723-1730.

Frei, H., Oxland, T. R., Rathonyi, G. C., and Nolte, L. P., 2001, "The Effect of Nucleotomy on Lumbar Spine Mechanics in Compression and Shear loading," Spine, Vol. 26, No. 19, pp. 2080-2089.

Frei, H., Oxland, T. R., and Nolte, L. P., 2002, "Thoracolumbar Spine Mechanics Contrasted Under Compression and Shear Loading," Journal of Orthopaedic Research, Vol. 20, No. 6, pp. 1333-1338.

Gangi, A., Kastler, B. A., and Dietemann, J. L., 1994, "Percutaneous Vertebroplasty Guided by a Combination of CT and Fluoroscopy," American Journal of Neuroradiology, Vol. 15, No. 1, pp. 83-86.

Gatt, C. J., Jr., Hosea, T. M., Palumbo, R. C., and Zawadsky, J. P., 1997, "Impact Loading of The Lumbar Spine During Football Blocking," American Journal of Sports Medicine, Vol. 25, No. 3, pp. 317-321.

Goel, V. K., Ramirez, S. A., Kong, W., and Gilbertson, L. G., 1995, "Cancellous Bone Young's Modulus Variation Within the Vertebral Body of a Ligamentous Lumbar Spine - Application of Bone Adaptive Remodeling Concepts,"
Journal of Biomechnical Engineering, Vol. 117, No. 3, pp. 266-271.

Hongo, M., Abe, E., Shimada, Y., Murai, H., Ishikawa, N., and Sato, K., 1999, "Surface Strain Distribution on Thoracic and Lumbar Vertebrae Under Axial Compression. The Role in Burst Fractures," Spine, Vol. 24, No. 12, pp. 1197-1202.

Kayanja, M. M., Ferrara, L. A., and Lieberman, I. H., 2004, "Distribution of Anterior Cortical Shear Strain After a Thoracic Wedge Compression Fracture," Spine J, Vol. 4, No. 1, pp. 76-87.

Kayanja, M. M., Togawa, D., and Lieberman, I. H., 2005, "Biomechanical Changes After The Augmentation of Experimental Osteoporotic Vertebral Compression Fractures in The Cadaveric Thoracic Spine," Spine J, Vol. 5, No. 1, pp. 5563.

Kayanja, M. M., Schlenk, R., Togawa, D., Ferrara, L., and Lieberman, I., 2006, "The Biomechanics of 1, 2, and 3 Levels of Vertebral Augmentation with Polymethylmethacrylate In Multilevel Spinal Segments," Spine, Vol. 31, No. 7, pp. 769-774.

Keller, T. S., Kosmopoulos, V., and Lieberman, I. H., 2005, "Vertebroplasty and Kyphoplasty Affect Vertebral Motion Segment Stiffness and Stress Distributions: a Microstructural Finite-Element Study," Spine, Vol. 30, No. 11, pp. 1258-1265.

Kopperdahl, D. L., Roberts, A. D., and Keaveny, T. M., 1999, "Localized Damage in Vertebral Bone is Most Detrimental in Regions of High Strain Energy Density," Journal of Biomechanical Engineering, Vol. 121, No. 6, pp. 622-628.

Lin, E. P., Ekholm, S., Hiwatashi, A., and Westesson, P. L., 2004, "Vertebroplasty: Cement Leakage into the Disc Increases the Risk of New Fracture of Adjacent Vertebral Body," American Journal of Neuroradiology, Vol. 25, No. 2, pp. 175-180.

Lindsay, R., Silverman, S. L., Cooper, C., Hanley, D. A., Barton, I., Broy, S. B., Licata, A., Benhamou, L., Geusens, P., Flowers, K., Stracke, H., and Seeman, E., 2001, "Risk of New Vertebral Fracture in the Year Following a Fracture," the Journal of the American Medical Association, Vol. 285, No. 3, pp. 320-323.

Mathis, J. M., Petri, M., and Naff, N., 1998, "Percutaneous Vertebroplasty Treatment of Steroid-induced Osteoporotic Compression Fractures," Arthritis \& Rheumatism, Vol. 41, No. 1, pp. 171-175.

McLain, R. F., Yerby, S. A., and Moseley, T. A., 2002, "Comparative Morphometry of L4 Vertebrae: Comparison of Large Animal Models for the Human Lumbar Spine," Spine, Vol. 27, No. 8, pp. E200-206.

Melton, L. J., 3rd, Kan, S. H., Frye, M. A., Wahner, H. W., O'Fallon, W. M., and Riggs, B. L., 1989, "Epidemiology of Vertebral Fractures in Women," 
American Journal of Epidemiology, Vol. 129, No. 5, pp. 1000-1011.

Polikeit, A., Nolte, L. P., and Ferguson, S. J., 2003, "The Effect of Cement Augmentation On the Load Transfer in an Osteoporotic Functional Spinal Unit: Finite-element Analysis," Spine, Vol. 28, No. 10, pp. 991-996.

Seino, H., Yamagata, M., Takahashi, K., Murata, Y., Suzuki, H., and Moriya, H., 2003, "Biomechanical Study of Human Cadaveric Lumbar Spine Reinforced by Newly Developed Hydroxyapatite Bone Cement," Journal of Orthopaedic Science, Vol. 8, No. 1, pp. 50-54.

Shah, J. S., Hampson, W. G., and Jayson, M. I., 1978, "The Distribution of Surface Strain in the Cadaveric Lumbar Spine," Journal of Bone and Joint Surgery-British Edition, Vol. 60-B, No. 2, pp. 246-251.

Verlaan, J. J., Dhert, W. J., Verbout, A. J., and Oner, F. C., 2005, "Balloon Vertebroplasty in Combination With Pedicle Screw Instrumentation: a Novel
Technique to Treat Thoracic and Lumbar Burst Fractures," Spine, Vol. 30, No. 3, pp. E73-79.

Verlaan, J. J., van de Kraats, E. B., Oner, F. C., van Walsum, T., Niessen, W. J., and Dhert, W. J., 2005, "The Reduction of Endplate Fractures During Balloon Vertebroplasty: a Detailed Radiological Analysis of The Treatment of Burst Fractures Using Pedicle Screws, Balloon Vertebroplasty, and Calcium Phosphate Cement," Spine, Vol. 30, No. 16, pp. 1840-1845.

Verlaan, J. J., van de Kraats, E. B., Oner, F. C., van Walsum, T., Niessen, W. J., and Dhert, W. J., 2005, "Bone Displacement and the Role of Longitudinal Ligaments During Balloon Vertebroplasty in Traumatic Thoracolumbar Fractures," Spine, Vol. 30, No. 16, pp. 1832-1839.

Manuscript Received: Jan. 18, 2007 Revision Received: Mar. 15, 2007 and Accepted: Apr. 02, 2007 